\title{
Inheriting library cards to Babel and Alexandria: contemporary metaphors for the digital library
}

\author{
Paul Gooding $^{1}$ (i) $\cdot$ Melissa Terras $^{2}$
}

Received: 18 January 2016 / Revised: 18 August 2016 / Accepted: 25 August 2016 / Published online: 22 September 2016

(C) The Author(s) 2016. This article is published with open access at Springerlink.com

\begin{abstract}
Librarians have been consciously adopting metaphors to describe library concepts since the nineteenth century, helping us to structure our understanding of new technologies. As a profession, we have drawn extensively on these figurative frameworks to explore issues surrounding the digital library, yet very little has been written to date which interrogates how these metaphors have developed over the years. Previous studies have explored library metaphors, using either textual analysis or ethnographic methods to investigate their usage. However, this is to our knowledge the first study to use bibliographic data, corpus analysis, qualitative sentiment weighting and close reading to study particular metaphors in detail. It draws on a corpus of over 450 articles to study the use of the metaphors of the Library of Alexandria and Babel, concluding that both have been extremely useful as framing metaphors for the digital library. However, their longstanding use has seen them become stretched as metaphors, meaning that the field's figurative framework now fails to represent the changing technologies which underpin contemporary digital libraries.
\end{abstract}

Keywords Digital libraries - Metaphor · Theory · Babel · Alexandria

Paul Gooding

p.gooding@uea.ac.uk

Melissa Terras

m.terras@ucl.ac.uk

1 School of Art, Media and American Studies, University of East Anglia, University Plain, Norwich NR4 7TJ, United Kingdom

2 Department of Information Studies, University College London, Gower Street, London WC1E 6BT, United Kingdom

\section{Introduction}

In Neil Gaiman's seminal comic book series Sandman, Dream, the anthropomorphic personification of one of seven universal concepts, punishes author Richard Madoc for a series of horrific crimes by overwhelming his mind with a flood of ideas. As Madoc descends into a madness caused by this supernatural information overload, he crouches down and blurts out a series of half-formed ideas for stories:

Two old women taking a weasel on holiday... Gryphons shouldn't marry. Vampires don't dance... A man who inherits a library card to the Library of Alexandria [1].

Madoc's exclamations are, at the risk of descending into parody, a metaphor for this article on metaphor. In his tortured outpouring of ideas, we see the negative impact of information overload and the commensurate inevitability that someone will eventually mention the Ancient Library of Alexandria.

Over recent years, library and information science (LIS) and related fields have written extensively on digital libraries. Many of these writers have relied heavily on metaphorical constructs to explain these developments, and this paper presents a study of two of the more ubiquitous of these metaphors: Jorge Luis Borges' [2] fictional Library of Babel and the historic Library of Alexandria. We will use quantitative and qualitative analysis to explore how these metaphors are used in the Anglophone LIS literature, their development through time, and how their ubiquity may affect our understanding of the concepts they have come to represent. The chosen cases represent just two of many metaphors for the digital library ${ }^{1}$ [5] and library technologies, but their preva-

\footnotetext{
${ }^{1}$ Examples of these metaphors abound in the literature: O'Day and Nardi [3] study some of these high-level metaphors for technology,
} 
lence makes them useful for our purposes: an exploratory study which attempts to apply data-driven and qualitative approaches to the study of metaphors in LIS.

Previous studies have explored library metaphors, noting the historical importance of metaphor for establishing meaning in the field. There have also been qualitative studies of metaphor, using either close textual analysis or ethnographic methods to investigate their usage. However, this is to our knowledge the first study to use bibliographic data and corpus analysis to explore how metaphors are adopted and used in relation to digital libraries. The term "digital library" has been contested [6-9], but we have interpreted it widely to include a number of related concepts: the Web, the universal digital library, the changing role of libraries in the digital age, and the concept of information overload. The chosen metaphors embrace these issues and more. In light of this, we will seek to answer the following research questions:

- How are the metaphors of the Library of Alexandria and the Library of Babel used to explain digital library concepts?

- How extreme are the uses of the chosen metaphors, and does this extremity differ depending on how they are used?

- What impact has the use of these metaphors had on how we, as a field, study the issues surrounding digital library technologies?

The following section will look briefly at the wider nature of metaphors to indicate the importance of metaphorical expressions in building before relating it more closely to the context of libraries.

\section{Literature review}

\subsection{Metaphors and human expression}

Lakoff and Johnson [10] have been hugely influential in building our understanding of the role of metaphor in everyday human communication. They demonstrated that metaphors are pervasive in everyday life, arguing that this pervasiveness goes beyond viewing metaphor merely as a "device of the poetic imagination and the rhetorical flourish" [10], instead playing a key role in structuring our conceptual systems, both in terms of how we think and how we act. Metaphors serve the important purpose of framing new concepts in relation to existing, better-established concepts that are understood to share common features. As Krippendorf [11] explains: "all metaphors carry explanatory structures

Footnote 1 continued

while Tokar [4] notes that the term "digital library" is itself a metaphor that has been used for the Internet. from a familiar domain of experiences into another domain in need of understanding or restructuring [author's emphasis]." Lakoff expands upon this point, noting that whereas metaphor was previously understood to be a linguistic phenomenon, the locus of metaphor is in thought not language. Metaphor is, then:

A major and indispensable part of our ordinary, conventional way of conceptualizing the world, and... our everyday behaviour reflects our metaphorical understanding of experience [12].

The process of 'norming' new ideas occurs through entailments, which structure a metaphor and provide it with extended characteristics which more effectively transfer ideas from the metaphorical concept to the other [13]. Metaphor therefore helps us to understand new or complex concepts by mapping similarities to more familiar concepts. In the case of new technologies, metaphor is a particularly valuable tool because of our incomplete understanding. Gooding et al. have previously proposed that debates around technological innovations tend towards the hyperbolic, and that the social adoption of particular technologies can be partly understood through the myths that surround them $[14,15]$. As such, despite their power for exploring new conceptual domains, metaphors for digital libraries also have the power to constrain and define our thinking:

The very systematicity that allows us to comprehend one aspect of a concept in terms of another... will necessarily hide other aspects of the concept. In allowing us to focus on one aspect of a concept..., a metaphorical concept can keep us from focusing on other aspects of this concept that are inconsistent with the metaphor [10].

Hamilton [16] further notes that as long as a metaphor remains "new", the originality and impact of the relationship between the metaphor and the concept alert the reader to look for parallels. Yet, the widespread adoption of an inappropriate metaphor can constrain thinking in undesirable ways. It is therefore an opportune moment to consider Babel and Alexandria's role as library metaphors, given that they have now become shorthand for certain concepts in LIS. First, we will pause briefly to consider how metaphors have been considered by library practitioners and researchers to date.

\subsection{Metaphors in library and information science}

Metaphor has been deployed as an explanatory tool for the entire modern library era. Giesecke [17] argues that librarians have been consciously adopting metaphors to describe concepts in librarianship since the modern library movement's origins in the late nineteenth century. These metaphors appear to have been important in the formative period of 
modern libraries, with Nardini [18] claiming that it was common for librarians to choose figurative language to express their vision of libraries: "metaphor was not only a way to describe the role of the library but also a way to explore possibilities, even a way to imagine possibilities in the first place." Early modern librarians adopted metaphorical frameworks to explore their particular social and political vision of libraries. Giesecke traces this conscious approach to establishing metaphor to the modern day, describing the purpose of developing metaphors within his own library service:

To help our own librarians and staff imagine new roles, cope with change, climb outside the box, and repackage our service. We have also tried different ways to help the university administration, faculty and students view the library as a vital, relevant part of the scholarly enterprise [17].

This conscious process of establishing metaphors contributes to our understanding of complex or novel ideas, for better of worse. In 1994, Ackerman declared that metaphors for new information utilities such as the Internet would structure our understanding of these utilities, while warning that they were already distorting and misrepresenting key concepts. For Ackerman, the term "digital library" was problematic; he argued that utopian visions of the digital library were encroaching, and that they misled us by exaggerating impact and downplaying the significance of social factors in technological adoption. These factors included the social aspects of library services and the human interaction between readers and trained information professionals, whereas the "library" component of the digital library had come to represent isolated information behaviour. In this example, utopian metaphors had redefined the social phenomenon in terms of what is already possible, rather than the technology's own unique features: it "considers only what is possible with specific types of technology, and then restricts the meaning of the metaphorical referent to that narrow conception [author's own emphasis]" [5].

Selecting metaphors can be taken either as a conscious attempt to point towards a particular figurative domain, or an evocation of a pre-existing domain. Yet, the metaphors we refer to in this article have also become so ubiquitous that they have become objects of parody. The Library of Alexandria, for example, has its own series of Web-based memes: ${ }^{2}$

\footnotetext{
${ }^{2}$ As with many memes, it is not entirely clear where this image originated; however, this is part of a wider meme entitled "You Know You're a History Fan When...". For further information on the meme see http://weknowmemes.com/2014/01/you-know-youre-ahistory-fan-when- $2 /$.
}

\section{YOU KNOW YOU'RE A HISTORY FAN WHEN}

\section{YOU STILL GET UPSET THINKING ABOUT THE LIBRARY OF ALEXANDRIA.}

Whereas early modern librarians defined their own conceptual space, and contemporary librarians still attempt to do so, the Web provides a platform where metaphors can be coopted, remixed and returned to us with unintended meanings [19]. This is driven by overuse of particular metaphors and has severe implications for their meaning in the future.

Our study is certainly not the first to consider the role of metaphors in LIS; a number of previous studies have been undertaken. Studies of metaphor in libraries have been largely historical and theoretical in nature [17,18,20,21]. Kennedy, for instance, sought to investigate the following question:

What is the significance of this sheer breadth of metaphors surrounding the library? Are these metaphors nothing more than insubstantial flourishes or is there some value in considering metaphors as revelatory expressions of perceptions of the library, worthy of study as conscious or unconscious mechanics for criticism or catalysts for change? [20]

Kennedy is not the only one to explore metaphors directly. Smith and Yachnes [22] published the results of a qualitative case study that investigated the underlying metaphors which staff and patrons relied upon when thinking about electronic texts. They conducted open-ended interviews with a few staff and four users of an electronic text service to investigate the language used to understand a digital resource for electronic texts. With this small sample, they noticed the repetition of some metaphors that varied between the staff and user. They identified that staff were more likely to describe the resource in playful terms, as a candy shop, or toy shop: in this metaphor, users were depicted as excited children, and staff were there to teach and guide them. Users, on the other hand, used more utilitarian schema, describing the resource as a tool with specific utility [22]. The variance between staff and users suggests that these metaphors were communal and specific to each community, allowing interviewees to understand digital resources in terms that made sense to them.

The next step in analysing metaphors for libraries is to do so at a larger scale. Smith and Yachnes write that this will allow for the identification of clusters of meaning: 
Individual metaphors, scripts and schemas, as mental shortcuts, may be quite specific to the mind that employs them. However, within a contextualized case study, or across a number of such studies, categories of meaning may cluster to provide sufficient explanatory power [22].

The task of exploring a wide selection of digital library metaphors is beyond the modest resources of this study, with just two chosen for detailed analysis: the Library of Babel, and the Library of Alexandria. There are a few reasons for choosing these specific metaphors. First, the frequency of their appearance in the literature is striking, which suggests that they represent a powerful metaphorical schema for contemporary debates around digital libraries. While this observation was subjective on the part of the authors, we were motivated to look objectively at how they had become so common and how they were used as a result. Second, they are frequently used as oppositional metaphors: Alexandria, as an ideal for the universal library, and Babel, as a cautionary tale of the dangers of information overload. Both represent literary and historical models which have been of enduring value to those investigating contemporary ideas of the library. We therefore felt that it was valuable to investigate the ideas and assumptions that were attached to these metaphors, through a process of empirical analysis rather than depending on an implied understanding of their role in the literature. The following section briefly introduces the genesis of these metaphors.

\subsection{The library of Babel}

Jorge Luis Borges, who was employed as the Director of the Argentinian National Library from 1955, first published the short story The Library of Babel in 1941. Later translated into English in 1962, the story described a library analogous to the universe, which consists of an enormous number of interlinked hexagonal rooms. The bookshelves within each room house books that contain every possible combination of just 25 basic textual characters. The library is therefore effectively infinite ${ }^{3}$ and contains all human knowledge past, present and future. This knowledge is surrounded by a vast majority of nonsense, erroneous texts or outright misleading versions, with no way of discerning between them. The scale of the universe, and the lack of any order to the books within, renders the library's knowledge utterly inaccessible. Borges tells the story of a society which wrestles with the nature of

\footnotetext{
${ }^{3}$ In fact, Bloch [23] has written an extremely engaging book that works out the mathematics of the library based on textual evidence: he concludes that, while not infinite, it would hold $25^{1,312,000}$ books, and points out that if each book were the size of a grain of sand, the entire universe could only hold a fraction of the books housed within Babel.
}

knowledge when it is simultaneously universal and utterly useless. Kennedy [20] writes that:

The opening line of Borges' 'The Library of Babel'", one of the most enduring and affecting literary representations of the library, immediately alerts the reader to the overarching portrayal of the library as an allencompassing, yet ultimately unknowable realm.

Although just a short story, the enduring nature of the concept of the Library of Babel has meant that other authors have returned to this concept numerous times since [24-29], drawing upon its rich imagery as a source of inspiration within the academic discourse and beyond.

\subsection{The Library of Alexandria}

The Ancient Library of Alexandria, based on the City of Alexandria in Egypt and founded by Ptolemy I Soter, functioned as a major centre of scholarship from its construction in the third century BC until its destruction: a date of much disagreement, but likely to have been after 48BC [30]. The library, reputed to be one of the most significant collections in the ancient world, contained hundreds of thousands of scrolls, many apparently confiscated from ships that made harbour in Alexandria with copies created by scribes and returned to the original owner [31]. As a result, LIS scholars [32] have speculated that it contains an almost complete collection of the major works of the Ancient Era, lost entirely when it was destroyed. ${ }^{5}$ This is of course impossible to ascertain, but the extent of the library's collection was significant by the standards of the era ${ }^{6}$. The Library of Alexandria is therefore frequently referred to as the first universal library, and provides a powerful metaphorical schema for the potential of repeating this achievement using digital technologies.

\section{Methodology}

Studies investigating metaphors in LIS have been generally qualitative in nature, so it was necessary to look elsewhere for suitable methods to answer our research questions. Terras'

\footnotetext{
4 The opening line is "The universe (which others call the Library) is composed of an indefinite and perhaps infinite number of hexagonal galleries, with vast air shafts in between, surrounded by very low railings" [2].

5 Among modern classical scholars, it is worth reading MacLeod's [33] account, which investigates the origins and size of the Alexandrian collection with reference to primary sources from contemporaries of the Library.

${ }^{6}$ Estimates place the extent of the collection at between 300,000 and 700,000 scrolls. Macleod [33] estimates that the average scroll would have been roughly equivalent to a chapter of a modern book, giving a maximum collection size of around 100,000 books in modern terms.
} 
previous work with Williams and Warwick [34] on studying the scholarly literature surrounding the use of a specific technological platform (Twitter) provided an initial methodological approach which was adapted for the aims of this research. The chosen methodology comprised three phases: first, in the data collection phase, relevant publications were identified; second, metadata and full text of relevant sections were analysed to assess publication dates, word frequencies, and usage patterns for each metaphor, and cross-citation patterns; and third, the relevant sections of each paper were qualitatively coded using content analysis [35] to analyse how each metaphor was deployed.

\subsection{Data collection}

The aim of the data collection phase was to gather a list of English language publications ${ }^{7}$ which mention the Library of Babel, the Library of Alexandria, or both, in relation to digital libraries. Researchers can identify papers through several methods, including searching in electronic databases or the open Web, and chaining from existing papers [34]. The six characteristics of search, as defined by Ellis [36], are "starting, chaining, browsing, differentiating, monitoring and extracting", and Green [37] reports the importance for humanities scholars of finding resources by "following bibliographic references from documents already known to them or to their colleagues." However, we chose not to follow citations from the resources we discovered, on the basis that there were too many citations to manually check given that only a few would have references to the metaphors in question. Therefore we relied on database and Web-based searching, with the date range left open to allow the inclusion of early examples of each metaphor. We considered it necessary to use the open Web in combination with Google Scholar, ${ }^{8}$ Scopus ${ }^{9}$ and Web of Science; ${ }^{10}$ due to the fact that metaphors are found in inline text, titles and abstracts, the ability to search the full text was vital. Difficulties arose because both search terms were extremely similar to other common terms which fell outside the scope of this study. Specifically, there was overlap between the ancient Library of Alexandria and two modern libraries with the same name, ${ }^{11}$ and between the

\footnotetext{
$\overline{7}$ Given the broadness of sources in library science and related areas, we took publications to mean blog posts, books, conference papers, journal articles, magazine and newspaper articles, and other grey literature including theses, reports and presentations.

${ }^{8}$ https://scholar.google.co.uk/.

9 http://www.scopus.com/.

10 http://webofknowledge.com.

11 The first is the modern Library of Alexandria, which was inaugurated in 2002 in the Egyptian city of Alexandria. Inspired largely by the historic Library of Alexandria, it was built close to the site of the ancient library. The second is the Library of the Louisiana State University at Alexandria. Although not directly related in the same way as the first
}

Library of Babel and the Tower of Babel. ${ }^{12}$ It was therefore necessary, although time consuming, to thoroughly check all the results found in full text searches before including them in the study. Resources were then collated in a Zotero ${ }^{13}$ group library to facilitate sharing, with a simple folder structure and tagging system to assist in retrieval and sorting. A full text search of the document was undertaken, with all mentions of each metaphor and its surrounding words copied and pasted into Zotero notes attached to each bibliographic record. A total of 432 resources for both metaphors were discovered.

\subsection{Data analysis}

Once the data collection phase was concluded, the resources were categorized according to their type, with the following categories applied: blog posts; books; conference papers; journal articles; magazine/newspaper articles; other. ${ }^{14}$ First, bibliographic metadata was exported from Zotero as a CSV file for analysis in Excel. This considered word frequency in titles, the distribution of publication dates, the types of publication where metaphors were found, and the rate of growth of each metaphor through time. Second, the full text notes were exported from Zotero as TEI-compliant $\mathrm{XML}^{15}$ for analysis in Voyant Tools, ${ }^{16}$ and the quotes were analysed for word frequency, the number of direct quotes from the text of the Library of Babel and to assist in identifying usage patterns for each metaphor. Finally, the quotes were used to qualitatively explore citations: we looked at resources which contained the most frequently used quotes from the text of the Library of Babel to discover whether they cited other papers found in the sample, to identify whether particular texts were recognized as the catalyst for these metaphors. Additionally, we analysed a sample of 50 randomly selected journal articles which mentioned the Library of Alexandria,

\footnotetext{
Footnote 11 continued

example, it was still responsible for providing a number of unrelated search results.

12 The Tower of Babel is a biblical story told in the Book of Genesis, and provides an explanation for the origin of different languages. As a result, it is commonly used as a metaphor in both computer science and LIS.

13 Zotero (https://www.zotero.org/) is a research tool for collecting, organizing, citing and sharing research sources. The group library function allows multiple users to share, annotate and tag sources online.

14 The other category included theses, presentations, Web pages and reports.

15 TEI stands for the Text Encoding Initiative, a community of practice in the Digital Humanities which is responsible for defining an XML format to present texts for online research, teaching and publication. The group website is http://www.tei-c.org/index.xml.

16 Voyant Tools is a free, online environment for text analysis, which provides a number of tools that can be used to prompt close reading, or visualize trends in writing, among other things. It is freely available at http://voyant-tools.org/.
} 
Table 1 Categorization scheme for sentiment analysis of publications in sample

\begin{tabular}{lll}
\hline Classification & Format & Details of categories \\
\hline Topic & Fixed & Books (encompassing books in digital and print form) \\
& Digital libraries (encompassing general digital library \\
& discussion and specific characteristics of digital libraries) \\
& Google books and related projects (encompassing Google \\
& projects, which represent a significant sub-category of the \\
& literature) \\
& Information Age (encompassing more general discussions \\
& which draw on the concepts of digital information and the \\
& information society) \\
& Libraries (encompassing more general library discussions, \\
& particularly around the concept of the universal library) \\
& WWW (encompassing articles which focus on the Web or the \\
& Internet) \\
& & -5 (extremely negative) $,-4,-3,-2,-1$ \\
& 0 (neutral) \\
Positivity & $1,2,3,4,5$ (extremely positive) \\
& Brief reference \\
& Extended metaphor \\
& Title
\end{tabular}

to ascertain whether they referred to a classical ${ }^{17}$ or histori$\mathrm{cal}^{18}$ source: in other words, whether reference to the Library were evidenced by a primary or secondary source.

\subsection{Qualitative analysis}

The qualitative analysis took the form of open coded classification based on the publication's full text, a method which facilitates delineation of concepts [38] and has been used successfully in previous studies to analyse titles [34,39,40]. Our categorization focused on high-level topics for each publication. Additionally, we undertook sentiment weighting ${ }^{19}$ by hand to ascertain how positively each metaphor was used on average. A variety of automated sentiment analysis methods exist, but human coding can still provide a useful method of analysis when nuance needs taking into account [41]. We therefore used hand coding for our sentiment analysis, with two raters independently rating the entire dataset. The joint probability of agreement for the raters was $78.16 \%$, and there were very few cases where the raters disagreed by more than two points on the scale. The results are therefore reasonably reliable given the small number of raters used. All results are reported as an average of the two ratings. The sentiment was weighted on how positively each metaphor was pre-

\footnotetext{
$\overline{17}$ This is taken to mean a primary source from Ancient Greece.

18 This is taken to mean a secondary source, which studies the history of Ancient Greece, and the Library of Alexandria.

19 Sentiment weighting is one facet of the method of sentiment analysis, which refers to the use of text analysis and computational language processing to identify subjective information from sources.
}

sented within the publication, rather than whether the article itself was positive. ${ }^{20}$ Where multiple mentions of the same metaphor were made, the rating referred to the overall tone of the metaphor. An 11-point scale was used, ranging from -5 for extremely negative sentiment to 5 for extremely positive, with 0 representing a neutral sentiment. Table 1 shows the classifications used for coding, including a brief explanation of each category:

\section{Findings}

The findings are presented in two sections: the first contains the results from analysing bibliographic metadata and full text, while the second presents the findings from the qualitative classification. Examples drawn from particular publications are used throughout to enrich the analysis.

\subsection{Bibliographic information}

In total, 432 resources were discovered, with Table 2 showing a detailed breakdown of how these were constituted:

Academic journals provide the majority of publications in our corpus, and books the second largest category. Conference papers were not strongly represented, although this may be because their full text is relatively inaccessible. In addition, 36 blog posts, 25 magazine or newspaper articles,

\footnotetext{
${ }^{20}$ For instance, Babel could be presented as a negative contrast to an article's central positive argument, or as a supporting argument for a more negative argument.
} 
Table 2 Breakdown of publications in sample by type of publication and mention of Alexandria or Babel

\begin{tabular}{|c|c|c|}
\hline Resource type & Mentions & $\begin{array}{l}\text { Number of } \\
\text { resources (\% } \\
\text { of publication } \\
\text { type) }\end{array}$ \\
\hline \multirow[t]{3}{*}{ Blog posts } & Alexandria only & $17(47.2)$ \\
\hline & Babel only & $18(50)$ \\
\hline & Both & $1(2.8)$ \\
\hline \multirow[t]{3}{*}{ Books } & Alexandria only & $22(27.8)$ \\
\hline & Babel only & $42(53.2)$ \\
\hline & Both & $15(19.0)$ \\
\hline \multirow{3}{*}{$\begin{array}{l}\text { Conference } \\
\text { papers }\end{array}$} & Alexandria only & $10(32.3)$ \\
\hline & Babel only & $19(61.3)$ \\
\hline & Both & $2(6.4)$ \\
\hline \multirow[t]{3}{*}{ Journal articles } & Alexandria only & $116(49.4)$ \\
\hline & Babel only & $101(43.0)$ \\
\hline & Both & $18(7.6)$ \\
\hline \multirow{3}{*}{$\begin{array}{l}\text { Magazine/newspaper } \\
\text { articles }\end{array}$} & Alexandria only & $11(42.3)$ \\
\hline & Babel only & $13(50)$ \\
\hline & Both & $2(7.7)$ \\
\hline \multirow{3}{*}{$\begin{array}{l}\text { Other } \\
\text { (Websites, } \\
\text { grey } \\
\text { literature, } \\
\text { etc.) }\end{array}$} & Alexandria only & $6(24)$ \\
\hline & Babel only & $19(76)$ \\
\hline & Both & $0(0)$ \\
\hline \multirow[t]{3}{*}{ Total } & Alexandria only & $182(42.1)$ \\
\hline & Babel only & $212(49.1)$ \\
\hline & Both & $38(8.8)$ \\
\hline
\end{tabular}

and 25 publications classified as other were found. Babel was mentioned more frequently than Alexandria by publications in our corpus, with $49.1 \%$ mentioning Babel, $42.1 \%$ mentioning Alexandria and the remaining $8.8 \%$ mentioning both. Journal articles were the only category where Alexandria was more frequently mentioned. This could suggest that Alexandria is more commonly engaged in academic discourse, while the dominance of Babel in books suggests that authors may prefer to draw on literary references in long form.

We used bibliographic information to analyse patterns in publication dates. Figure 1 shows the number of publications in each year, presented cumulatively by the type of metaphor used:

Figure 2 shows the rate of growth of each metaphor, measured as a percentage of the total number of publications of each type:

These charts should be treated with caution because we cannot ascertain the representativeness of our corpus in com-

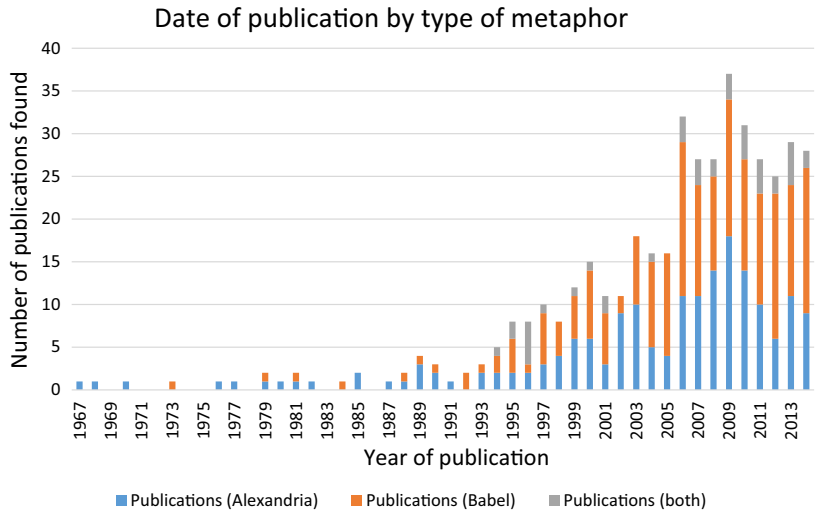

Fig. 1 Table showing the date of publication for all resources in the sample, broken down by the type of metaphor

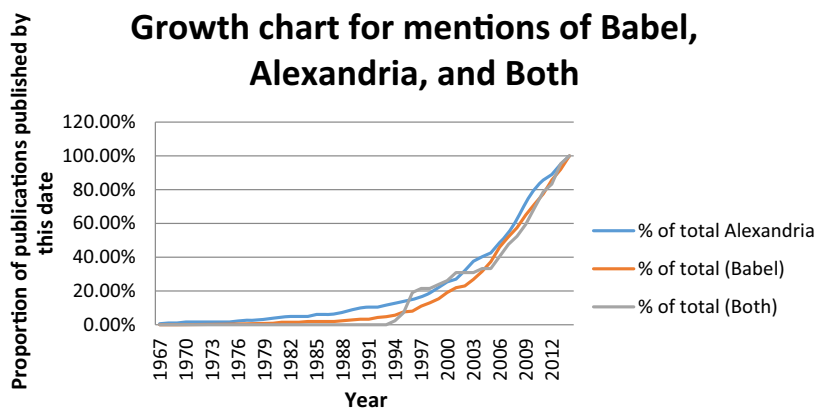

Fig. 2 Table showing the rate of growth for each metaphor, measured as a percentage of the total number of resources of that type

parison to all publications in LIS. Thus, both Figs. 1, 2, are presented as absolute measurements based solely on our dataset. The increase in recent years could therefore be explained by increased publication rates, new media types or improved availability of resources in recent years: given that the Web has facilitated discovery, it is possible that the apparently precipitous increase in the use of these metaphors in recent years is linked to wider trends in publishing.

With these cautionary points established, some tentative conclusions can be made. First, we can see that both metaphors have been used for a significant period of time. The first found metaphorical use of the Library of Alexandria within an LIS context was found in 1967, while the first use of Babel in this context was in 1973, 11 years after the story's translation into English. In our sample, both metaphors became commonplace in the 1990s, but it is in recent years that both metaphors have been extensively adopted, with a significant increase in relevant publications since 2005. While we are unable to ascertain how much of this trajectory is due to external issues, it is likely that the truth is that widespread availability of academic resources through the Web has increased exposure to these metaphorical schema, thereby increasing their profile and making them more likely to be adopted by others. 


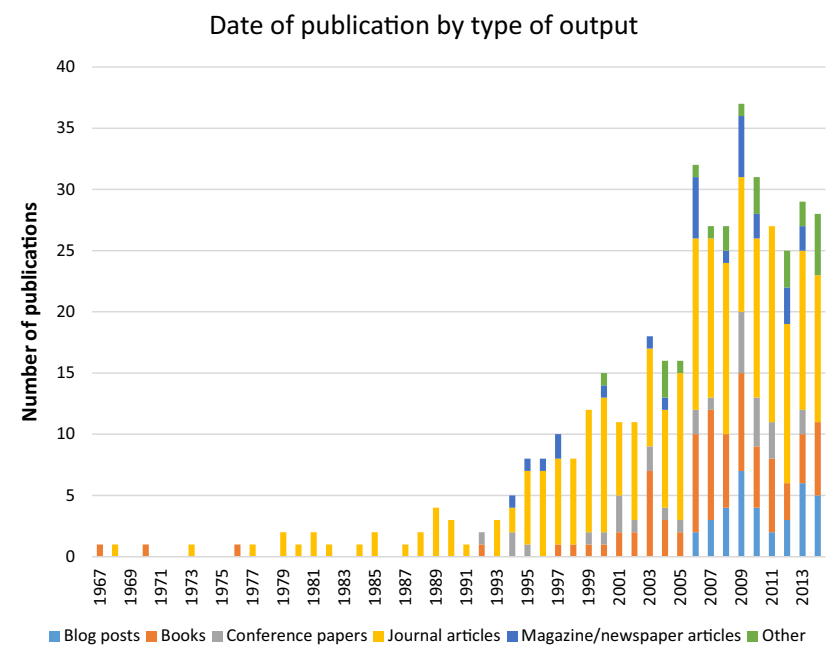

Fig. 3 Table showing date of publication, broken down by the type of resource

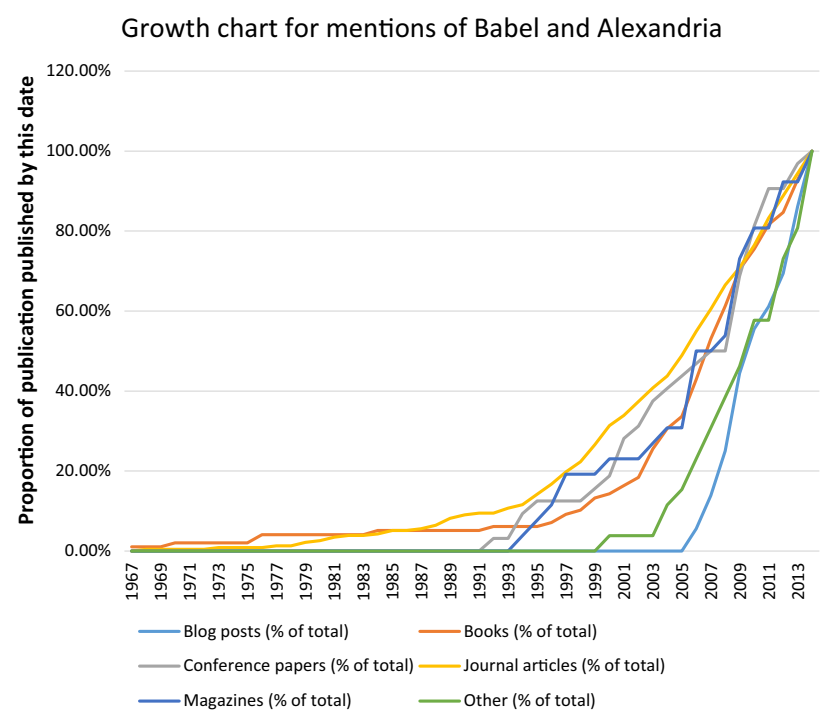

Fig. 4 Table showing growth rate of mentions of Babel and Alexandria combined, broken down by type of resource

Figure 3 shows publication dates broken down by the type of publication. The first chart shows the date of publication, presented cumulatively for all publication types:

Figure 4 shows the percentage growth of mentions of both metaphors, measured as a percentage of the total number of publications of each type:

The growth of blog posts from 2005, and other resources from 1999, certainly suggests that some of the recent growth in usage is down to new resource discovery channels, but rapid growth is seen for all resource types. The first book in the dataset was published in 1967, while the first journal article was published in 1968 . It took another 25 years to find other resource types adopting the metaphors, with the first conference paper found in 1992 and the first newspa-

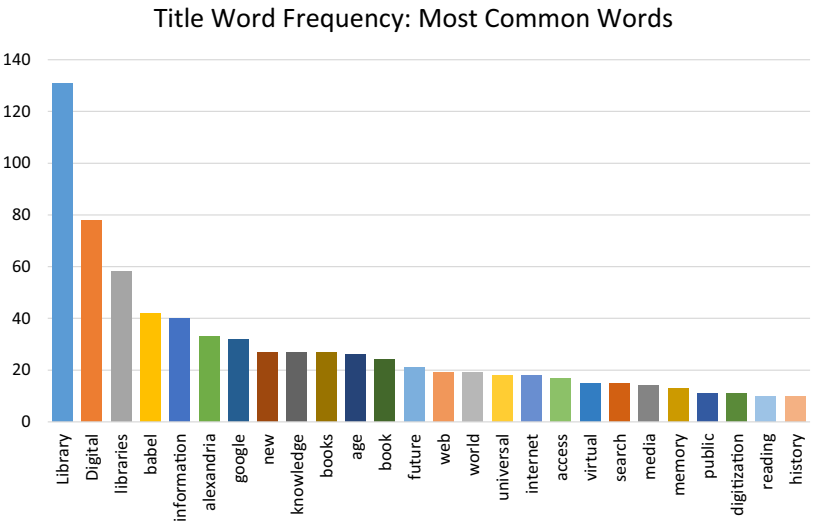

Fig. 5 Table showing most common words in titles of the whole sample (Babel and Alexandria)

per or magazine article in 1994. This point where existing metaphors begin to permeate mass communication channels is where the use of both metaphors begins to accelerate, with non-academic publications helping to drive wider adoption.

\subsection{Text analysis}

This section presents the results of text analysis, covering the titles and full text of publications in our corpus. The following chart shows the most commonly mentioned words in all titles, measured by word frequency (Fig. 5):

The most common words were found to be "library", "digital" and "libraries", demonstrating the close link between Babel, Alexandria and digital library concepts. Both Babel and Alexandria appear in the top ten, while the remaining words represent a few loosely grouped themes: technological (google, internet, digitization); temporal (new, future, age, history); and intellectual (knowledge, reading, memory).

A similar word frequency was found when the analysis was extended to the entire corpus of article quotes. Figure 6 was created in Voyant Tools using the supplied "stop words" list to eliminate common or irrelevant words to derive the top twenty:

The key words are reasonably consistent between titles and our corpus. "Library" remains the most common word, but technological words decrease in frequency. Instead, intellectual concepts are more frequently mentioned: "information" and "knowledge" are in the top five, showing a shift away from the technological towards a more thematic approach to digital libraries. While titles focus on technological concepts, then, authors expand upon these points in the full text to relate the metaphors, and their related technological concepts, towards wider intellectual considerations. 


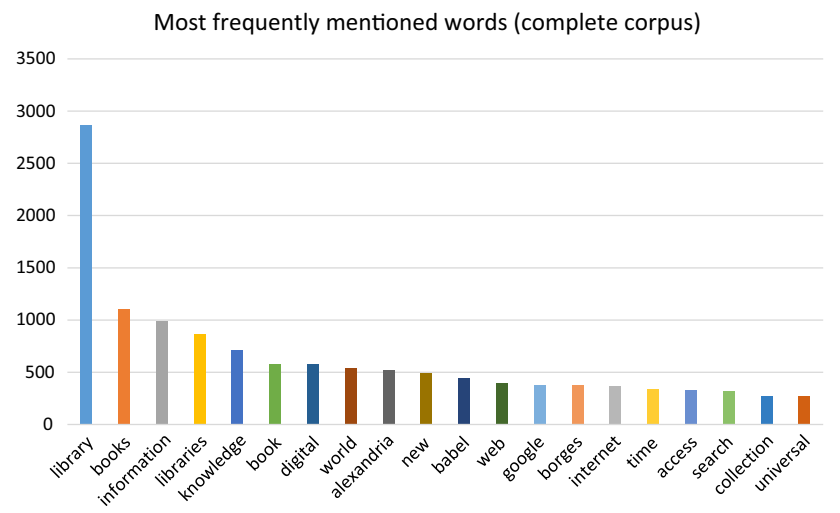

Fig. 6 Table showing most common words in corpus (Babel and Alexandria)

Distribution of positivity for mentions of Alexandria and Babel

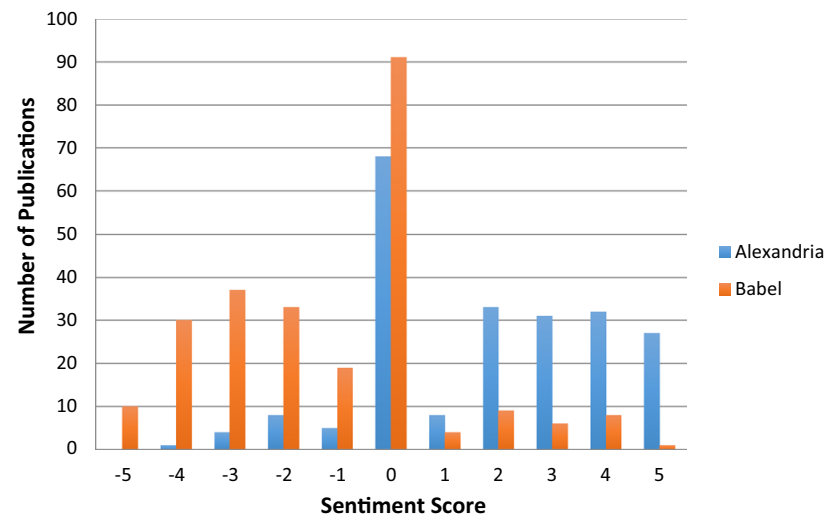

Fig. 7 Table showing distribution of sentiment scores for publications mentioning Alexandria and Babel

\subsection{Sentiment analysis of metaphors}

Finally, we present the results of the sentiment analysis. Papers were ranked from -5 (extremely negative) to 5 (extremely positive) based on how positively they represent each metaphorical concept. The first chart shows the distribution of positivity for mentions of Alexandria and Babel (Fig. 7):

The vast majority of mentions for both metaphors are neutral, which we will show later correlates strongly with brevity of usage: in these cases, each metaphor is often used to refer to a communal figurative framework rather than to progress a specific argument. It was also surprising to find that a minority of publications viewed the Library of Babel as a positive metaphor for the universal library, where we expected the opposite. ${ }^{21}$ The majority of writers, though, placed Alexan-

${ }^{21}$ One could uncharitably assume that these people had not read the story, but this is unlikely to be the case. Rather, we found that a minority of writers focused on the positivity of the universal aspect of the

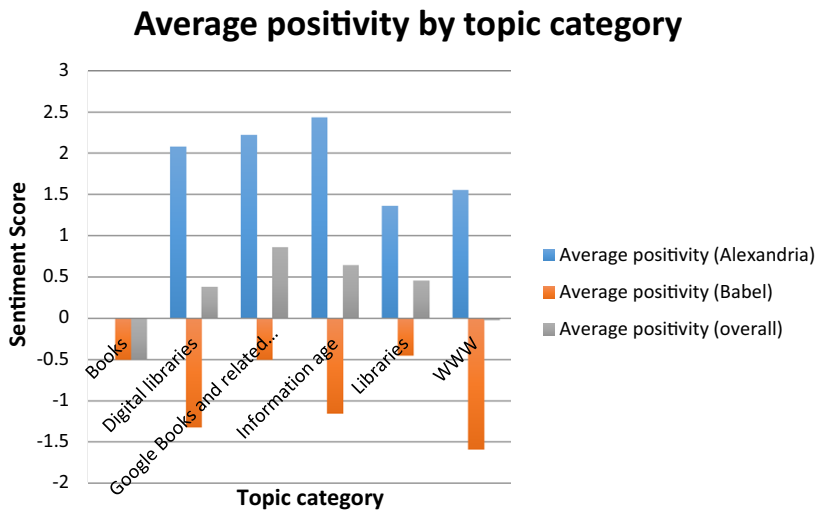

Fig. 8 Table showing average sentiment score by topic category of publication

dria and Babel either directly or indirectly in an oppositional framework. Alexandria is generally considered to be positive, with an average positivity of 1.81, while Babel has an average positivity of -1.17 . However, Babel was rarely used extremely negatively, suggesting a degree of nuance in its use. We attribute this to two factors. The first is the nuanced nature of the source text, which considers both the excitement and frustration of the users of Borges' universal library. The second is that Alexandria has been co-opted as a metaphor to market corporate digitization programmes such as Google Books. ${ }^{22}$ As the following chart shows, publications that discuss Google Books are the most likely to present Alexandria in a positive light (Fig. 8):

This positivity towards Alexandria is indicative of its adoption by the corporate sphere, but it extends beyond mass market communications into the academic literature, such as Frosio's [43] enthusiastic depiction:

The idea of the Library of Alexandria has powerfully expanded over the centuries, embodying the dream of universal wisdom and knowledge centralized in one place. Digitization projects, such as the Google Books project, are reviving the hope that this dream may come true... Today the entire collection of human knowledge may be only one click away.

Overall, texts which refer to Alexandria in relation to Google Books, Digital Libraries and the Information Age, score very highly in their positivity. Babel is used most negatively in relation to digital libraries and the Information Age, representing the metaphor's use as a polemical counterpoint in the technological debate. The most negative use of the Babel

Footnote 21 continued

Library of Babel, rather than the majority who viewed its scale and impenetrability as a negative.

${ }^{22}$ Indeed, Sergey Brin's [42] New York Times piece directly refers to the library, arguing that Google Books provides a way to avoid the destruction of cultural heritage that occurred. 
metaphor is for the Web itself, suggesting a strong correlation in the corpus between the metaphor and the idea of Web search as unordered and ineffective in comparison to the more ordered approach in resources more recognizable as digital libraries.

As we alluded to earlier, the extent of the metaphor is linked to differing patterns of positivity. Brief references, for instance, were found to be more neutral than extended metaphors. For Alexandria, the average positivity for brief references was 1.55, compared to 2.55 for extended metaphors. For Babel, there was an average positivity of -0.65 for brief references and -2.12 for extended metaphors. This suggests that extended metaphors are used to make a specific rhetorical point that tends towards the extremes of our positivity scale. Brief references are more likely to treat each metaphor as an existing concept which will be familiar to existing readers, and on average are written in a more neutral tone. This suggests two differing types of metaphor in our corpus:

- Metaphor as touchstone: authors use established metaphors, which are alluded to briefly and presented in a relatively neutral tone.

- Metaphor as rhetorical device: authors go into more depth, using the metaphor as the basis for a particular extended, and generally more polemical, rhetorical viewpoint.

\section{Discussion: specifics of the Babel and Alexandria metaphors}

This section approaches the Babel and Alexandria metaphors separately, to explore how each is used in practice.

\subsection{Quoting the library of Babel}

First, we have looked at how frequently specific passages from the Library of Babel have been quoted in our corpus. The story lends itself to this kind of analysis, as it is extremely short and has some passages which are heavily cited. The table in Appendix A shows how frequently each passage has been quoted in our sample. This analysis shows three quotes that are cited over ten times in the corpus, and their prominence gives us an insight into how Babel is conceptualized as a metaphor. The third most frequently cited passage, found 12 times, is:

There must exist a book which is the formula and perfect compendium of all the rest: some librarian has gone through it and he is analogous to a god [2].

This passage is often used as a metaphor for the importance of search and classification in making sense of large-scale collections. As Welsh [44] comments:
In a large collection, much less Borges's imagined universal library, without finding aids, without catalogues, without a classified shelving order or a suggested route through, nothing can be found.

Authors have wisely disavowed the self-aggrandizing possibility offered by the librarian as god analogy, even in the context of the universal library [45-47]. Instead, they use this passage to explore the complexities of knowledge organization and retrieval at scale. It is quoted, therefore, not as a claim for the elevated status of librarians, but as a parallel in fiction to make sense of the demands of information discovery in massive digital environments.

The second most frequently used passage, found 26 times, is:

The Universe (which others call the Library) [2].

This line is often used as a direct metaphor for large-scale online libraries, drawing on the idea of the universal library. The frequency with which it is used suggests a focus on scale in the literature, and the Babel metaphor is particularly relevant. Babel therefore becomes a point of comparison for the universal, or indeed merely unfathomably large, libraries of the digital age, and its negative connotations allow authors to extend their discussion to the perceived problems of digital libraries and Web-scale information discovery:

The universe (which others call the Web) is exactly what this book is about. And the universe is not always a happy place... Today we stand at the epicentre of a revolution in how our society creates, organizes, locates, presents, and preserves information-and misinformation... It's hard to make sense of this maelstrom; we feel confused, disoriented, unconfident, wary of the future, unsure even of the present [48].

The most quoted passage was found 42 times in our corpus and refers to the moment of realization among the inhabitants of Babel that their library was indeed universal:

When it was proclaimed that the Library contained all books, the first impression was one of extravagant happiness [2].

This is a snippet of a longer paragraph that is sometimes quoted in full. It is extremely evocative, serving as a metaphor for the conflicting emotions of users of large-scale information networks. It hints at the initial feeling of excitement that massive digital libraries instil in users, and the resultant feeling of disappointment when reality does not live up to this potential. For many, it predicts both the promise and the frustration of information overload via digital platforms. Sebastiani [49], for instance, claims that the Web is a "faithful enactment of Borges' library:

Any Web user has surely experienced the "happiness" and "depression" Borges speaks of, in first realizing 
that the Web contains enormous amounts of useful information just a few clicks away, and in then realizing that without appropriate tools one might need to access huge quantities of irrelevant information before hitting on the relevant items.

Yet in our sample the "extravagant happiness" felt towards a new technology is more frequently referenced than the frustration. This mirrors our own theoretical work on the status of technology as a manifestation of the sublime [14]. Indeed, Borges' own reference to the downsides of the universal library is quoted just nine times:

As was normal, this inordinate hope was followed by an excessive depression [2].

Many of these nine examples combine "extravagant happiness" with "extreme depression" to make a similar point to Sebastiani. The earliest examples occurred in 1999 [50,51], but over 15 years later the metaphor has sustained itself despite the development of improved discovery tools to help mitigate the worst of information overload: Breitbach [52], for instance, wrote the following in 2012:

In Jorge Luis Borges' famous short story The Library of Babel, a universal library exists where every possible book is located... Because of the continued failure of users to understand the library's organization, many go mad, commit suicide or become paranoid. Although the author of this chapter does not anticipate such calamity as libraries adopt Web-Scale Discovery Systems (WSDS), there are a wide range of potential problems libraries need to consider before we reach the stage of extravagant happiness.

The Babel metaphor therefore remains widely utilized, despite the fact that significant developments in digital library discovery render the comparison between the unordered chaos of Borges' library and the increasingly ordered digital library less relevant with time.

\subsubsection{Cross-citations for the library of Babel}

We undertook citation analysis of all the resources which cited the three most popular quotes from The Library of Babel to see what patterns of cross-citation could be identified. We have not dwelled on the findings to date, and this is largely because we discovered that just one of the resources cited another from this sample: specifically, Patten and McElligot [53] cited Roger Chartier's The Order of Books [54]. Given that there is no textual evidence that this citation is for the purpose of recognizing the Babel metaphor, it is far more likely this solitary citation is due to the influence of Chartier's book. We would note that academic citation practices make the process of identifying the genesis of particular metaphors difficult: many papers choose to present their chosen metaphor as if it has been freshly coined by the author, as in the following example:

I wish to draw the reader's attention to an even earlier and more indirect theorization of the universal digital library, one found in Jorge Luis Borges's 1941 short story "The Library of Babel" [55].

This is not the only example where an existing figurative schema is presented as a novel insight, and we will see later that authors cite Borges' text rather than an inspiration from within LIS. Whether due to a desire to claim ownership of the metaphorical space or an implicit understanding of the communal nature of these metaphors, the result is difficulty in tracking the adoptions of metaphors through citations. It is therefore difficult to identify which texts acted as originators within LIS, and whether a particular publication proved influential in driving wider adoption of the metaphors.

\section{2 "Ever since the library of Alexandria..."}

Babel provides a source text for close analysis by authors, who have used it in LIS research to build a conceptual framework for discussing the negative aspects of digital libraries. Beyond this, it also fulfils the role of an archetypal universal library whose impact is considered predominantly negative. The Ancient Library of Alexandria represents the opposite archetype, embodying the positive aspects of the universal library. In the last 20 years, the Alexandrian library has become synonymous with a surprisingly wide range of library concepts. It exists in much of the literature as a call to Antiquity, tracing the roots of librarianship through over 2000 years to a notional original universal library. This call to antiquity is a frequently deployed rhetorical device, often approximating the phrase "ever since the ancient Library of Alexandria" [56-58]. Alexandria is thus more than a metaphor for the universal library. Based on varying interpretations of its history, it represents a cultural day zero for libraries, an 'Ur-library' which is apparently responsible for myriad contemporary library practices and concerns, including: storage of primary records [59]; storage capacity problems [56] and the resultant remote storage facilities [60]; preservation of historic publications [61]; service-based librarianship [62]; collection evaluation and bibliographic control [63]; metadata, when defined generally as "data on data" [64]; and, most frequently, it is described as the first universal library [57,65-67].

\subsubsection{Citing sources for the Library of Alexandria}

To ascertain how Alexandria has become such a versatile metaphor, we analysed a sample of 50 journal articles from the corpus to see whether the section which referred to 
Alexandria cited a classical or historical source, or a source which did so. We found that ten $(20 \%)$ of the articles did so. One further article cited Wikipedia. The proportion of articles citing an external source was therefore higher than for Babel, where authors relied on reference to the short story itself when they felt citation to be necessary. There was one particular source from within LIS which proved influential to the Alexandrians: five articles chose to cite Berti and Costa's "the Ancient Library of Alexandria: A Model for Classical Scholarship in the Age of Million Book Libraries" [68] as a source in their discussion of the library. This article stands out among our corpus because it deploys a variety of classical and historical sources to build a case for the relevance of Alexandria to modern digital libraries. Since 2009, it has therefore become a common source of evidence for those using the Alexandrian metaphor, and yet the authors sound a note of warning about the strength of the historical record:

Given the fortune of the traditions about the Alexandrian library, it can seem somewhat contradictory to point out that the historical sources on it are surprisingly scanty. But the truth is that we can say almost nothing certain about it: where and how the papyrus scrolls were stored; what dimensions its collections really had... Even the information about the end of the library refers to a space of six centuries, from the age of Caesar to the age, as we have seen, of the prophet Muhammad [68].

In light of this important point, it is worth noting that 39 $(78 \%)$ of the sample did not cite any sources in their use of the metaphor. This may tell us something about academic citation practices, but it also suggests the importance of the Alexandrian metaphor as a figurative space rather than a factual representation of institutional characteristics. While there is no doubt about its existence, the lack of sources which map its scope and objectives has left a mythical space in which writers can adapt the metaphor to represent such a variety of digital library concepts. It is this that allows writers to use the metaphor in so many different ways: rather than relying on the scant evidence to recall what little is known of the library, we have redefined and remixed it to meet our own needs in illustrating a complex innovation. Thus, Alexandria has become a mutable myth, recomposed and remixed to represent anything, and indeed almost everything that is seen as worthy of praise in the twenty-first century digital library.

\section{Conclusion}

This paper has given a detailed account of how the metaphors of Alexandria and Babel are present in LIS literature, and how each is respectively identified with positive and negative representations of these concepts. We therefore turn to our final question: what impact has the use of these metaphors had on how we, as a field, study the issues surrounding digital library technologies? We refer back to Lakoff and Johnson [10], who point out that metaphors are not merely linguistic flourishes, but play a key role in shaping our everyday behaviour. Features of Babel and Alexandria are extremely useful as framing metaphorical concepts, but their longstanding use has seen them used increasingly in contexts where the metaphor is stretched, or where it fails to adapt to the changing technological contexts of the digital library. Web search, for instance, is in many respects far removed from Borges' library, where the former can return relevant results through algorithmic search programmes, the latter remains resolutely inaccessible. Alexandria provides a strong metaphor for the universal library, but has been adopted for so many other concepts that it is difficult to differentiate between the myth of Alexandria and the original library's true contemporary relevance.

These two metaphorical libraries also come with an inherent, widely understood value judgement that ensures that referring to one or the other almost inevitably aligns the writer in an ongoing polemical debate around digital libraries. The use of such divisive metaphors has tied our field's figurative framework to a widely adopted system of relative values, whereby particular metaphors can be clearly linked to how positively an author views digital libraries and Web-scale discovery. As such, we would argue that both metaphors have subsumed and thereafter helped to fuel the polemical debate and that they can therefore obscure a middle ground where the nuances of technological adoption truly lie. Babelian and Alexandrian metaphors therefore begin to restrict the meaning of digital libraries to reflect existing metaphorical schema rather than what is technically possible. In particular, they limit us to big questions of scale, universality and information overload, rather than assisting us in understanding the growth and adoption of digital libraries over the past decades.

The question, for those reading this article, is what may happen to these metaphors as a result of such a conscious examination of their usage. An intervention such as this runs the risk of forcing others to stop using them, thus removing what have clearly become valuable figurative reference points in LIS research. Clearly, metaphors provide a useful way of understanding innovations in digital libraries, and it would be a shame to see useful metaphors fall into disuse purely because their prevalence has been noted. Instead, we hope that this article will lead to a critical appraisal of the role of these metaphors in contemporary debates. We have shown that the Libraries of Babel and Alexandria have been subsumed into the field, and that this has led to their emergence as widely understood archetypes which can be evoked with little further though to their relevance. We would encourage readers to wield these metaphors self-consciously; in other words, to consider whether the metaphors they use are truly suited to the task of describing modern digital libraries. 
While there have been other studies into the use of metaphors in relation to libraries, this is to our knowledge one of the first to adopt a large-scale approach. It uses bibliographic data, corpus analysis, qualitative sentiment weighting and close reading to analyse particular metaphors in detail. This paper builds on the authors' previously published work, providing examples of how metaphors are used to build a figurative framework for discussing digital libraries in Library and Information Science. We study the Library of Babel and the Library of Alexandria, which have both been widely represented as metaphors, and latterly archetypes, for digital libraries in LIS writing and criticism.

The paper tracks the growth of both metaphors through time, finding that they both emerged in the literature in the late 1960s and early 1970s, before becoming increasingly common in the mid-1990s and virtually ubiquitous in the twenty-first century. We demonstrate that both metaphors have become increasingly common in recent years and that they appear to have originated in the academic literature. We also demonstrate through keyword analysis that the thematic concerns of papers which cite the metaphors are primarily focused on common technological, temporary and thematic grounds, and that the Alexandrian metaphors are generally considered positive while Babel is constructed negatively. Therefore, we conclude that the increasing ubiquity of these metaphors, combined with the polemical way they are used, serves to entrench a polarized approach to digital libraries and Web-scale discovery, rather than adapting to reflect emerging issues and technological developments.

The role of metaphor in understanding complex technological concepts in LIS is ripe for further work, and we plan to consider this issue further. This study was based on publications until 2014, and new publications should be added to the corpus to facilitate a longitudinal study into how these metaphors evolve in the future. We would also note that, while these metaphors have certainly been widely adopted, they are only two of many that are used in this context. We would therefore like to undertake future work which expands the range of our analysis by identifying and analysing other key metaphors. As a pilot study, the methods adopted have proven valuable in evaluating the chosen metaphor within the Anglophone literature. However, a larger study that tracks a wider range of metaphors would extend these insights into more general conclusions about the nature of metaphors for digital libraries. There is also a need to evaluate how these metaphors are used in different languages; it would be particularly valuable to compare these results to the Spanishlanguage literature, as this was the first published language of Borges' story. Given the time-intensive nature of the literature review and hand coding of sentiment weighting, a larger study would also need to consider how to automate aspects of data collection and analysis, perhaps by limiting its search to the full text archive of specific LIS journals. It would also be valuable to compare the sample to a corpus of papers on similar topics which do not reference either Babel or Alexandria. Finally, further work should seek to contextualize these findings through qualitative methods that interrogate them from the point of view of critics and library users, given the changing role of libraries in our society and the ongoing growth of digital library platforms, such work would help us to interrogate and adapt our conceptual frameworks over time.

This work will provide a starting point for further interrogation of the metaphors which we use to describe emerging technologies. We hope it will lead all of us, including the authors ${ }^{23}$ to more carefully consider how we describe technologies through metaphor, and to adopt a conscious approach to developing and representing metaphors of the digital library to better represent their current scope and potential.

Open Access This article is distributed under the terms of the Creative Commons Attribution 4.0 International License (http://creativecomm ons.org/licenses/by/4.0/), which permits unrestricted use, distribution, and reproduction in any medium, provided you give appropriate credit to the original author(s) and the source, provide a link to the Creative Commons license, and indicate if changes were made.

\section{IJDL Appendix A}

Quotations from the Library of Babel [2], by frequency of mention in our sample corpus

\begin{tabular}{ll}
\hline Quote & Times used \\
\hline "I had but few friends left, and & 1 \\
those, I stopped seeing. A & \\
prisoner of the Book, I hardly left \\
my house... At night, during the \\
rare intervals spared me by \\
insomnia, I dreamed of the \\
book." \\
"For every sensible line of \\
straightforward statement, there \\
are leagues of senseless \\
cacophonies, verbal jumbles and \\
incoherences." \\
"One: the library is so enormous \\
that any reduction of human \\
origin is infinitesimal." \\
"The certitude that everything has \\
been written negates us or turns \\
us into phantoms." \\
"Light is provided by some \\
spherical fruit"
\end{tabular}

${ }^{23}$ We have, for instance, been known to use both Babel and Alexandria as metaphorical constructs in our own work [69]. 


\begin{tabular}{|c|c|}
\hline Quote & Times usec \\
\hline $\begin{array}{l}\text { "It does not seem unlikely to me } \\
\text { that there is a total book on some } \\
\text { shelf of the universe; I pray to the } \\
\text { unknown gods that a man - just } \\
\text { one, even though it were } \\
\text { thousands of years ago! - may } \\
\text { have examined and read it." }\end{array}$ & 2 \\
\hline $\begin{array}{l}\text { "In truth, the Library includes all } \\
\text { verbal structures, all variations } \\
\text { permitted by the twenty-five } \\
\text { orthographical symbols, but not a } \\
\text { single example of absolute } \\
\text { nonsense... No one can articulate } \\
\text { a syllable which is not filled with } \\
\text { tenderness and fear, which is not, } \\
\text { in one of these languages, the } \\
\text { powerful name of a god." }\end{array}$ & 2 \\
\hline $\begin{array}{l}\text { "This vast library is useless, } \\
\text { rigorously speaking, a single } \\
\text { volume would be sufficient, a } \\
\text { volume of ordinary format, } \\
\text { printed in nine or ten-point type, } \\
\text { containing an infinite number of } \\
\text { infinitely thin leaves." }\end{array}$ & 2 \\
\hline $\begin{array}{l}\text { "I know of an uncouth region } \\
\text { whose librarians repudiate the } \\
\text { vain and superstitious custom of } \\
\text { finding a meaning in books and } \\
\text { equate it with that of finding a } \\
\text { meaning in dreams or in the } \\
\text { chaotic lines of one palm." }\end{array}$ & 2 \\
\hline $\begin{array}{l}\text { "These examples made it possible } \\
\text { for a librarian of genius to } \\
\text { discover the fundamental laws of } \\
\text { the Library. This thinker } \\
\text { observed that all the books, no } \\
\text { matter how diverse they might } \\
\text { be, are made up of the same } \\
\text { elements: the space, the period, } \\
\text { the comma, the twenty-two } \\
\text { letters of the alphabet." }\end{array}$ & 2 \\
\hline $\begin{array}{l}\text { "I know of the feverish library } \\
\text { whose chance volumes are } \\
\text { constantly in danger of changing } \\
\text { into others and affirm, negate and } \\
\text { confuse everything like a } \\
\text { delirious divinity." }\end{array}$ & 2 \\
\hline $\begin{array}{l}\text { "I venture to suggest the solution to } \\
\text { the ancient problem: the Library } \\
\text { is unlimited and cyclical." }\end{array}$ & 2 \\
\hline $\begin{array}{l}\text { "The Library is a sphere whose } \\
\text { exact center is any one of its } \\
\text { hexagons..." }\end{array}$ & 3 \\
\hline
\end{tabular}

Quote

Times used

"There are official searchers,

3

inquisitors. I have seen them in the performance of their function: they always arrive extremely tired from their journeys; they speak of a broken stairway which almost killed them; they talk with the librarian of galleries and stairs; sometimes they pick up the nearest volume and leaf through it, looking for infamous words. Obviously, no one expects to discover anything."

"At that time a great deal was said about the Vindications: books of apology and prophecy which vindicated for all time the acts of every man in the universe and retained prodigious arcana for his future."

"These pilgrims disputed in the narrow corridors, proffered dark curses, strangled each other on the divine stairways, flung the deceptive books into the air shats, met their death cast down in a similar fashion by the inhabitants of remote regions. Others went mad."

"The other: every copy is unique, irreplaceable but (since the Library is total) there are always several hundred thousand imperfect facsimiles: works which differ only in a letter or a comma"

"The impious maintain that nonsense is normal in the library..."

"I suspect that the human species the unique human species - is on the road to extinction, while the Library will last on forever: illuminated, solitary, infinite, perfectly immovable, filled with precious volumes, useless, incorruptible, secret."

"First: The Library exists ab 5 aeterno" 


\begin{tabular}{|c|c|}
\hline Quote & Times used \\
\hline $\begin{array}{l}\text { "Men usually infer from this } \\
\text { mirror that the Library is not } \\
\text { infinite (if it were, why this } \\
\text { illusory duplication?); I prefer to } \\
\text { dream that its polished surfaces } \\
\text { represent and promise the } \\
\text { infinite" }\end{array}$ & 5 \\
\hline $\begin{array}{l}\text { "At that time it was also hoped that } \\
\text { a clarification of humanity's } \\
\text { basic mysteries - the origin of the } \\
\text { Library and of time - might be } \\
\text { found." }\end{array}$ & 5 \\
\hline $\begin{array}{l}\text { "In the vast Library there are no } \\
\text { two identical books." }\end{array}$ & 7 \\
\hline $\begin{array}{l}\text { "As was natural, this inordinate } \\
\text { hope was followed by an } \\
\text { excessive depression." }\end{array}$ & 9 \\
\hline $\begin{array}{l}\text { "There must exist a book which is } \\
\text { the formula and perfect } \\
\text { compendium of all the rest: some } \\
\text { librarian has gone through it and } \\
\text { he is analogous to god." }\end{array}$ & 12 \\
\hline $\begin{array}{l}\text { "The Universe (which others call } \\
\text { the library)" }\end{array}$ & 26 \\
\hline $\begin{array}{l}\text { "When it was proclaimed that the } \\
\text { Library contained all books, the } \\
\text { first impression was one of } \\
\text { extravagant happiness." }\end{array}$ & 42 \\
\hline
\end{tabular}

\section{References}

1. Gaiman, N.: The Sandman. DC Comics, New York (2010)

2. Borges, J.L.: The library of Babel. In: Yates, D.A., Irby, J.E. (eds.) Labyrinths: Selected Stories and Other Writings, pp. 54-55. New Directions, New York (1964)

3. O’Day, V.I., Nardi, B.A.: An ecological perspective on digital libraries. In: Bishop, A.P., Van House, N.A., Buttenfield, B.P. (eds) Digital Library Use: Social Practice in Design and Evaluation. MIT Press, Cambridge, MA (2003)

4. Tokar, A.: Metaphors of the Web 2.0: With Special Emphasis on Social Networks and Folksonomies. PhD Thesis, University of Dusseldorf, Dusseldorf (2008)

5. Ackerman, M.S.: Metaphors along the information highway. In: Proceedings of the Symposium on Directions and Impacts of Advanced Computing (DIAC'94), Cambridge, MA, pp. 1-5 (1994)

6. Candela, L., Castelli, D., Pagano, P., et al.: Setting the foundations of digital libraries: the DELOS manifesto. D-Lib Magazine 13. http://www.dlib.org/dlib/march07/castelli/03castelli.html (2007). Accessed 7 Jan 2016

7. Lagoze, C., Krafft, D.B., Payette, S., Jesuroga, S.: What is a digital library anymore, anyway? D-Lib magazine 11 . http://www.dlib. org/dlib/november05/lagoze/11lagoze.html (2005). Accessed 11 Jan 2016

8. Borgman, C.: Digital libraries and the continuum of scholarly communication. J. Doc. 56, 412-430 (2000)

9. Calhoun, K.: Exploring Digital Libraries: Foundations, Practice, Prospects. Facet Publishing, London (2014)

10. Lakoff, G., Johnson, M.: Metaphors We Live By. University of Chicago Press, Chicago (1980)
11. Krippendorf, K.: Major metaphors of communication and some constructivist reflections on their use. Cybern. Hum. Knowing 2, 3-25 (1993)

12. Lakoff, G.: The contemporary theory of metaphor. In: Metaphor and Thought, 2nd edn. Cambridge University Press, Cambridge (1992)

13. Johnston, R.: Salvation or destruction: metaphors of the internet. First Mon 14. http://firstmonday.org/article/view/2370/2158 (2009). Accessed 13 Jan 2016

14. Mosco, V.: The Digital Sublime: Myth, Power, and Cyberspace. MIT Press, Cambridge (2004)

15. Gooding, P., Terras, M., Warwick, C.: The myth of the new: mass digitization, distant reading, and the future of the book. Lit. Ling. Comput. 28(4), 629-639 (2013)

16. Hamilton, A.: Metaphor in theory and practice: the influence of metaphors on expectations. ACM J. Comput. Doc. 24, 237-253 (2000)

17. Giesecke, J.: Finding the right metaphor: restructuring, realigning, and repackaging today's research libraries. J. Libr. Adm. 51, 54-65 (2010)

18. Nardini, R.F.: A search for meaning: American library metaphors. Libr. Q. 71, 111-140 (2001)

19. Lessig, L.: Remix: Making Art and Commerce Thrive in the Hybrid Economy. Penguin Press, New York (2008)

20. Kennedy, C.: Metaphor: Library. University of Cape Town, Cape Town (2007)

21. Pomerantz, J., Marchionini, G.: The digital library as place. J. Doc. 63, 505-533 (2007)

22. Smith, M., Yachnes, P.: Scholar's playground or wisdom's temple? competing metaphors in a library electronic text center. Libr. Trends 46, 718-731 (1998)

23. Bloch, W.L.: The Unimaginable Mathematics of Borges' Library of Babel. Oxford University Press, Oxford (2008)

24. Flanagan, L.N.: Professionalism Dismissed. Coll. Res. Libr. 34(3), 209-214 (1973)

25. Langford, D.: The Net of Babel by J*rge L**s B*rg*s. Interzone, Cambs (1995)

26. Evans, N., Sasse, H.-J.: Searching for meaning in the Library of Babel: field semantics and problems of digital archiving. In: Researchers, Communities, Institutions, Sound Recordings, Sydney (2003)

27. Battles, M.: Library of Babel: Google Goes in Search of the Neverending Book. Boston Globe, 26 December 2004 (2004)

28. Manguel, A.: The Library at Night. Yale University Press, New Haven (2008)

29. de Castro, P.: Librarians of Babel: A Toolkit for Effective Communication. Witney, Oxford (2009)

30. Thiem, J.: Myths of the universal library: from Alexandria to the postmodern age. Ser. Librarian Print. Page Digit. Age 26, 63-74 (1995)

31. Galenus, C.: Claudii Galeni Opera Omnia. Georg Olms, Hildesheim (1965)

32. Kruk, M.: The internet and the revival of the myth of the universal library. Aust. Libr. J. 48, 137-147 (1999)

33. Macleod, R.: The Library of Alexandria: Centre of Learning in the Ancient World. I.B. Taurus, London (2000)

34. Williams, S.A., Terras, M., Warwick, C.: What people study when they study twitter. J. Doc. 69(3), 384-410 (2013)

35. Krippendorf, K.: Content Analysis. International Encyclopedia of Communication, pp. 403-407. Oxford University Press, New York (1989)

36. Ellis, D.: A behavioural approach to information retrieval system design. J. Doc. 45, 171-212 (1989)

37. Green, R.: Locating sources in humanities scholarship: the efficacy of following bibliographic references. Libr. Q. 70, 201-229 (2000) 
38. Corbin, J., Strauss, A.: Basics of Qualitative Research: Techniques and Procedures for Developing Grounded Theory. Sage Publications, Thousand Oaks (2008)

39. Miller, K.J., Fullmer, S.L., Walls, R.T.: A dozen years of mainstreaming literature: a content analysis. Exceptionality 6, 99-109 (1996)

40. Ross, C., Terras, M., Warwick, C., Welsh, A.: Enabled backchannel: conference twitter use by digital humanists. J. Doc. 67, 214-237 (2011)

41. Jockers, M.: My Sentiments (Exactly?). Matthew L. Jockers, 4 January. http://www.matthewjockers.net/2015/04/01/my-sentimentsexactly/ (2015). Accessed 30 Apr 2015

42. Brin, S.: A library to last forever. The New York Times, New York (2009)

43. Frosio, G.F.: Google books rejected: taking the orphans to the digital public library of Alexandria. Santa Clara High Technol. Law J. 28, 81-141 (2011)

44. Welsh, A.: Knowledge Organization: the Universal versus the Canonical in The Library of Babel. Evening Salon: Collecting and Knowledge, the Library of Babel. http://ww.ucl.ac.uk/infostudies/ anne-welsh/outreach/Script.docx (2010). Accessed 31 Oct 2014

45. Abbott, A.: Professionalism and the future of Librarianship. Libr. Trends 46, 430-443 (1998)

46. Daly, M.: Forked Paths Fork. Master Thesis, Donau-Universität Krems (2008)

47. Langschied, L.: E-mail and beyond. Resour. Shar. Inf. Netw. 9, 39-59 (2010)

48. Witten, I., Gori, M., Numerico, T.: Web dragons: inside the myths of search engine technology. Morgan Kaufmann, San Francisco (2006)

49. Sebastiani, F.: Organizing and Using Digital Libraries by Automated Text Categorization. In: Proceedings of the AI*IA workshop on artificial intelligence for cultural heritage and digital libraries (2001)

50. Allsop, R., deLahunta, S.: Archive review. Perform. Res. J. Perform. Arts 4, 119-120 (1999)

51. Bruce, B.: Digital content: the Babel of cyberspace. J. Adolesc. Adult Lit. 42, 558-563 (1999)

52. Breitbach, W.: Web-scale discovery: a Library of Babel? In: Popp, M.P., Dallis, D. (eds.) Planning and Implementing Resource Discovery Tools in Academic Libraries. Information Science Reference, Hershey, PA (2012)

53. Patten, E., McElligot, J.: The Perils of Print Culture: Book, Print and Publishing History in Theory and Practice. PalgraveMacMillan, Basingstoke (2014)

54. Chartier, R.: The order of books: readers, authors, and libraries in Europe between the Fourteenth and Eighteenth Centuries. Stanford University Press, Stanford (1992)
55. Rowe, C.: The new library of Babel? borges, digitisation and the myth of the universal library. First Mon. 18. http://firstmonday.org/ ojs/index.php/fm/article/view/3237/3416 (2013). Accessed 21 Nov 2015

56. Agee, J., Naper, S.: Off-site storage: an analysis. Collect. Build. 26, 20-25 (2007)

57. McGregor, B.: Facets and hierarchies in scientific search. J. Electron. Publ. 11. http://quod.lib.umich.edu/j/jep/3336451.0011.205? view=text;rgn=main (2008). Accessed 12 Dec 2015

58. Smit, E., Van Der Hoeven, J., Giaretta, D.: Avoiding a digital dark age for data: why publishers should care about digital preservation. Learn. Publ. 24, 35-49 (2011)

59. Sauer, D.K.: English faculty and the postmodern library; or, is there any there there? Coll. Undergrad. Libr. 1, 127-137 (1994)

60. Shlomo, E.T.: Nicholson baker wasn't all wrong. Acquis. Libr. 15, 117-130 (2003)

61. Bishop, B.W., Grubesic, T.H., Prasertong, S.: Digital curation and the GeoWeb: an emerging role for geographic information librarians. J. Map Geogr. Libr. Adv. Geosp. Inf. Collect. Arch. 9, 296-312 (2013)

62. Cottrell, T.: Service increases fueling budget growth. Community Jr. Coll. Libr. 17, 15-21 (2011)

63. Faigel, M.: Methods and issues in collection evaluation today. Libr. Acquis. Pract. Theory 9, 21-35 (1985)

64. Nazim, M., Mukherjee, B.: Librarian's perceptions of knowledge management in developing countries: a case with Indian academic libraries. Int. Inf. Libr. Rev. 45, 63-76 (2013)

65. Jochum, U.: The Alexandrian library and its Aftermath. Libr. Hist. 15, 5-12 (1999)

66. Kresh, D.: The Whole Digital Library Handbook. ALA Editions, Chicago (2007)

67. Gustin, S.: Google Books Deal Bolsters Dream of Universal Bookstore. TIME, 8 October 2012, available online at http://business. time.com/2012/10/08/google-books-deal-bolsters-dream-of-univ ersal-digital-bookstore/ (2012). Accessed 12 Dec 2015

68. Berti, M., Costa, V.: The ancient library of Alexandria: a model for classical scholarship in the age of million book libraries. In: CLIR Proceedings of the international symposium on the scaife digital library (2009)

69. Gooding, P.: Mass digitization and the garbage dump: the conflicting needs of quantitative and qualitative methods. Lit. Linguist. Comput. 28, 425-431 (2013) 